\title{
LA TAREA DEL TEÓLOGO SEGÚN DOMINGO BÁÑEZ: ENTRE LA METAFÍSICA Y LA MÍSTICA
}

\author{
THE JOB OF THE THEOLOGIAN ACCORDING TO DOMINGO \\ BÁNEEZ: BETWEEN METAPHYSICS AND MYSTICS
}

\author{
JOSÉ ÁNGEL GARCÍA CUADRADO \\ Universidad de Navarra - IEHM
}

Recibido: 05/03/2020 Aceptado: 22/04/2020

\section{RESUMEN}

Para Domingo Báñez la especulación teológica necesita de la Metafísica: ambas tienen por objeto de estudio a Dios; el conocimiento teológico de Dios supone el conocimiento metafísico. Para la Metafísica, Dios es Acto puro de ser, y la gracia es una participación de ese Acto, una intensificación del acto de ser. Pero Dios no solo es una idea abstracta, sino un ser real, con quien es posible vivir en comunión mística. La Teología se cultiva con aprovechamiento cuando el teólogo tiene connaturalidad con la realidad divina; en definitiva, el santo está en condiciones óptimas para hacer Teología. Se mantiene así la unidad entre experiencia con el Dios vivo y el ejercicio de la especulación teológica que se creía rota desde la Edad Media.

Palabras clave: Dios, gracia, acto de ser, esencia, Teresa de Jesús, Tomás de Aquino. 


\section{ABSTRACT}

According to Domingo Báñez, theological speculation needs Metaphysics: both have God as their object of study; theological knowledge of God presupposes metaphysical knowledge. God is a pure Act of being, and the Grace is a participation in that Act, that is, an intensification of the act of being. Nevertheless, God is not only an abstract idea, but also a real being, with whom I can live intimately. Theology successfully develop when the theologian has connaturally with divine Reality; in short, the saint is in optimal situation to do Theology. The unity between experience with the living God and the work of theological speculation, which was thought to have been broken since the Middle Ages, is thus maintained.

Keywords: God, Grace, act of being, essence, Therese of Ávila, Aquinas.

En su famoso Memorial redactado la noche del 23 de noviembre de 1654, Pascal distingue dos concepciones sobre Dios: "Dios de Abraham, Dios de Isaac, Dios de Jacob, no de los filósofos y de los sabios. Certidumbre, certidumbre, sentimiento, gozo, paz. Dios de Jesucristo" (Pascal 2018, n. 913, 566). El Dios de los filósofos es, en realidad, una idea de la divinidad, abstracta, lograda por reflexión intelectual; mientras que el Dios de la fe es el alcanzado por el contacto vivo con Jesucristo, un ser real, vivo y concreto con el que se ha encontrado existencialmente. No es necesario añadir que Pascal apuesta no por el Dios abstracto o ideal, sino por el Dios-persona, que interpela como a Abraham, a Isaac, a Jacob. El Dios de la fe, el Dios-Jesucristo que llena de certeza y alegría.

El desdoblamiento entre la idea abstracta de Dios y el Dios personal es muy anterior, y procede -según el sentir de los estudiosos- del divorcio entre la Teología especulativa y la mística durante la Baja Edad Media (Vanderbroucke 1950; Huerga 1966; Klauck1970; Moioli 1978; Von Balthasar 1964). Según esta dicotomía, la teología escolástica tendría un carácter científico y abstracto; la mística, por el contrario, estaría más pegada a la experiencia concreta del creyente, con un fuerte componente afectivo y existencial. Una procede por vía de entendimiento; la otra por vía del amor ${ }^{1}$. Cuestionar o debatir las causas de esa separación, excede el propósito de este trabajo; me propongo más bien

1 En realidad, ya en la época medieval se manifestaron estas dos vías, pero es en la época moderna cuando el divorcio entre estas dos vías de acceso a Dios parece definitivo. 
comprobar si la gran tradición tomista española del siglo XVI -representada aquí por el dominico Domingo Báñez- está viciada por este divorcio.

La elección de este autor viene determinada por diversos motivos. En primer lugar, porque la historiografía actual tiende a presentarlo como típico representante de la teología especulativa y escolástica, con un cierto regusto racionalista que le lleva a cultivar una teología abstracta y metafísica, alejada de las cuestiones vitales (Vilanova 1989, 614; Andrés1977, 296-386; Belda 2000, 779794; Pena 2009, 163-169; Osuna 1997; Almeida 1976).

Por otro lado, Báñez aparece fuertemente ligado a la figura de santa Teresa de Jesús, de altas experiencias místicas y consciente de la necesidad de evitar los excesos de la devotio moderna (Montero 2015; Maroto 2009, 163-169; Alvira 1992, 39-50; Huerga 1963; Lépée 1947). A priori parece difícil armonizar las experiencias místicas de Teresa de Ávila y la metafísica abstracta de Báñez. Y, sin embargo, se dio una mutua influencia: Teresa de Jesús buscó en Báñez la seguridad doctrinal en un momento en que se recelaba de la mística por su posible relación con los alumbrados. Por su parte, la santa de Ávila influyó en el modo de hacer teología del maestro salmantino (García Cuadrado, 2016a).

Por último, Báñez es un fiel comentador de santo Tomás quien supo mantener la genuina unidad entre el saber místico y el especulativo. En efecto, Tomás de Aquino reconoce tres sentidos en la Sagrada Doctrina. En primer lugar, la Teología como ciencia de las conclusiones derivadas de los principios revelados, siguiendo el paradigma aristotélico de ciencia. En segundo lugar, el estudio histórico-positivo de las fuentes escriturísticas. Por último, la mística y la teología moral, como experiencia en la vida del creyente. Para el Doctor Angélico la Sagrada Doctrina nace del acto de fe y más concretamente de la vida y sabiduría cultivada por la fe. En otras palabras, la experiencia de Dios forma parte de la Sacra Doctrina; es más, viene a ser el fundamento y punto de partida de la reflexión teológica (Torrell 1998, 9-32). De este modo, las distinciones de las diversas disciplinas teológicas (dogmática, exégesis, moral y espiritual, etc.) encuentran en el hombre de fe, creyente y teólogo, su unidad.

\section{METAFÍSICA Y SAGRADA DOCTRINA}

Báñez es bien conocido por la controversia sobre la gracia que marcó la teología de la segunda mitad del siglo XVI, pero también por su pensamiento marcadamente metafísico. Todo parece indicar que nos encontramos frente a un buen representante de la corriente más intelectualista de la escolástica, alejado 
de la experiencia con el Dios vivo: la especulación metafísica, por su abstracción, parece alejarnos de la experiencia concreta de Dios.

Báñez se pregunta si la especulación metafísica está por encima de la reflexión teológica (Báñez 2020, a. 6, duda 1a , 158). Sin embargo, Báñez -al igual que su maestro Tomás- es eminentemente un teólogo, conocedor de los derechos de la ciencia de Dios. Por eso responde a la objeción así:

Ninguna ciencia, incluida la Metafísica, dirige a la Teología, sino que todas las ciencias la sirven, y sobre todo la Metafísica, de modo que con ella se verifica que lo más alto de lo inferior alcanza a lo ínfimo de lo superior. Así, es muy útil que el teólogo se ejercite en los principios metafísicos. Y desde luego, la misma Metafísica tiene una mayor brillantez y perfección cuanto se pone al servicio de la Teología que cuando ordena a las inferiores o se aprende aparte; lo cual está claro por la experiencia sobre todo en los que aprenden la Teología de santo Tomás, pues éstos, entre los demás, se convierten en los más eruditos en Metafísica. Concluimos, por tanto, que la Metafísica es dirigida y perfeccionada por la Teología (Báñez 2020, a. 6, duda 1a, ad 5, 163-164).

Así pues, siendo más elevada la Teología, la especulación metafísica es necesaria para la tarea del teólogo. Desde el primer artículo de la cuestión $1^{\mathrm{a}}$, Báñez distingue entre Teología y Metafísica. Ambas tienen por objeto a Dios, pero la Teología parte de la luz revelada, mientras que la Filosofía parte de la luz natural de la razón (Báñez 2020, a. 1, 78-79).

La Teología natural forma parte de la Metafísica: se dirige a Dios, pero atendiendo a las luces naturales de la razón, mientras que la Teología sobrenatural parte de la luz de la fe (Báñez 2020, a. 2, duda 2a , 107-111). La Metafísica se mueve en un alto grado de abstracción y ahí radica su dificultad (Báñez 2020, a. 2 , duda $\left.1^{\mathrm{a}}, 101\right)$. Por esto, la Metafísica parece ajena a la experiencia concreta y material. Si sitúa en el tercer grado de abstracción en el que se abstrae de la materia inteligible (Báñez 2020, a. 3, duda 1a , 127-129). Aunque lo considerado por la Metafísica sea una realidad corporal, es considerada en lo que tiene de eterna y necesaria.

En el pensamiento de Báñez, se le atribuye un mayor grado de abstracción a la ciencia teológica que a la Metafísica (Báñez 2020, a. 3, duda 1ª 121):

Nuestra Teología es verdadera y propiamente una ciencia, $[\ldots]$ conviene atribuirle las propiedades de la ciencia en cuanto sea posible. Una propiedad de la ciencia es que abstrae de la materia, y cuanto superior sea la ciencia, tanto más abstrae. Puesto que la Teología es la suprema entre las ciencias, su 
abstracción debe ser la máxima, y sobresaliente por encima de la abstracción metafísica (Báñez 2020, a. 3, duda 1ª 127).

Así pues, el peligro de alejar la especulación teológica de la experiencia concreta de Dios vivo se presenta muy real. Báñez, no edulcora esta doctrina. Dios es objeto tanto de la Metafísica como de la Teología: pero la abstracción propia de la Teología es mayor que la propia de la teología natural:

Si consideramos la abstracción propia de nuestra Teología con respecto a su objeto propio, encontraremos que supera en mucho a la abstracción metafísica. Objeto de nuestra Teología es Dios mismo, el cual según Sí mismo es acto puro y no tiene parte alguna material como tiene el ente, que es objeto de la Metafísica. [...]. Si el metafísico considera de algún modo a Dios, lo hace en cuanto puede brillar en los efectos naturales la fuerza divina y la divinidad; [...]. El teólogo en cambio trata de Dios mismo en cuanto es en Sí, y sin orden a los efectos naturales cognoscibles naturalmente. Por lo que Dios mismo, en cuanto se presenta como objeto a la Teología, se somete a la luz de orden superior que sólo dimana de Dios a nuestro intelecto, no como debido a nosotros por nuestra naturaleza, no consiguiente a nuestra quididad o eficiencia, como la luz natural y la luz adquirida están en nosotros. Por tanto, como el orden sobrenatural es superior a todo al orden natural, así lo que de por sí pertenece a este orden sobrenatural es más abstracto -según su propia razón- que lo inmaterial que pertenece al orden de la naturaleza (Báñez 2020, a. 3, duda $\left.1^{\mathrm{a}}, 128\right)$.

El objeto de la Teología natural y de la Teología sobrenatural ("nuestra Teología") es Dios mismo que no tiene nada de material: es un ser totalmente separado de la materia, puro espíritu, acto puro; para acceder a Él es preciso elevarse al mayor grado de abstracción. Parece imposible la comunicación de un ser tan puro y espiritual y una criatura que subsiste en la carne. Sin embargo, Dios no es inalcanzable; ni es "el Totalmente otro" de la teología protestante. Abstracción no significa para escolástico salmantino inaccesibilidad humana a Dios; sino más bien el recuerdo de la altísima dignidad a la que está llamada la naturaleza racional humana:

Esta pureza se manifiesta en la mejor de las acciones que es la visión de Dios, la cual hace deiforme a la criatura racional. Baste lo dicho hasta aquí para que entiendas lo grande y lo excelsa que es la abstracción de nuestra Teología. Las demás realidades que considera -es decir, lo que pertenece al orden de la naturaleza-lo asume en la medida en que se presupone al orden de la gracia de Dios o es susceptible de ordenarse a este orden; y esta es la causa de que el teólogo asuma tantas disputas lógicas, físicas y metafísicas: para que en 
todas ellas busque la diferencia de la naturaleza y la gracia, y juzgue de qué manera está sometida al orden de la naturaleza y esté ordenada al orden sobrenatural de la gracia: tan lejos está el que se le oponga (Báñez 2020, a. 3, duda $\left.1^{\mathrm{a}}, 129\right)$.

La visión de Dios es posible y lleva a la divinización de la criatura, a la transformación del hombre en Dios. Tal transformación esencial no puede ser exigida por la naturaleza, sino que es obra de la gracia divina. Parece abrirse así un puente entre la más alta abstracción especulativa y la experiencia del Dios vivo.

\section{METAFÍSICA DEL SER Y LA CUESTIÓN DE LA GRACIA}

Para el maestro salmantino la especulación metafísica guarda una estrecha relación con la ciencia de Dios. Pero ¿de qué Metafísica estamos hablando? ¿La metafísica del ente de la que Dios vendría a ser un Ente supremo? (Báñez 2020, a. 7, duda $\left.1^{a}, 167\right)$. Báñez no es muy explícito, pero da indicaciones suficientes para comprender mejor su propuesta metafísica del acto de ser, y de Dios como Acto puro de ser:

También en esta vida, aunque no perfecta y distintamente, conocemos la quididad de Dios: que Dios por su esencia es su ser, que es acto puro, que es trino en personas y uno en substancia; por lo que de este conocimiento tanto el metafísico como el teólogo pueden tener ciencia sobre Dios (Báñez 2020, a. 7 , duda $\left.1^{\mathrm{a}}, 173\right)$.

Así pues, más que una metafísica de la esencia, donde Dios sería la substancia con todos los atributos positivos o perfecciones posibles, el maestro salmantino apuesta por una metafísica del acto de ser, siguiendo fielmente los pasos de santo Tomás, frente a una concepción más formalista (Escoto) o esencialista (Suárez). Los conocedores del pensamiento bañeciano coinciden en destacar su metafísica del ser, en la que Dios aparece como Acto puro de cuya perfección del ser participan las demás criaturas. Este es el núcleo de la metafísica tomista que Báñez se esfuerza en reivindicar frente a las tendencias de la época (Vega 1954; Forment 1985; Bonino 1994; Orrego 2006, 195) como Gilson descubrió con asombro y acierto (García Cuadrado 2016b, 2018).

¿Qué incidencia puede tener una metafísica del acto de ser en la Teología? En Báñez su doctrina del ser se pone en relación con la vida de la gracia:

La Teología considera de modo inmediato a Dios mismo, y algunas propiedades que siguen a su ser, en cuanto se le reconoce principio del orden de la 
gracia. Lo demás lo considera no como partes que de por sí son pertinentes a Dios mismo, sino en cuanto de alguna manera son ordenables a Él en cuanto principio y fin de la gracia (Báñez 2020, a. 7, duda 1ª 175).

De esta doctrina parece desprenderse la idea de la gracia como una intensificación del acto de ser. Esta idea, sin embargo, no parece haberla desarrollado Báñez de manera explícita, aunque sí se halla tratada por sus discípulos, especialmente por Pedro de Ledesma (Ledesma 1596; Gea1960a, 1960b) en polémica con Juan Vicente de Astorga (Sánchez Sorondo 1977); posteriormente también Juan de Santo Tomás se hace eco de esta disputa (Urdanoz 1945; García Fernández 1946, 1947).

En la línea de la más clásica metafísica se afirma que el obrar sigue al ser (agere sequitur esse). A un actus essendi más perfecto le corresponden unas operaciones más perfectas. La capacidad operativa de una piedra es bastante limitada: se agota en el mero hecho de existir. Sin embargo, los seres con vida poseen un acto de ser más perfecto pues pueden realizar una serie de operaciones de las que carecen los seres inertes. Y el ser humano, gracias a su naturaleza espiritual, es capaz de realizar operaciones más altas que los meros seres vivos no realizan: conocer intelectualmente, obrar libremente y amar. El ser en los seres humanos se halla menos "constreñido" por su naturaleza. Dentro de los límites de la naturaleza humana, el ser humano puede crecer y desarrollar operaciones más perfectas. Un ser humano recién nacido no puede correr cien metros en diez segundos, cosa que un adulto debidamente entrenado podrá hacer. Esto se aplica mejor a las facultades espirituales: entender y amar pueden ampliarse con el cultivo y desarrollo de esas facultades, de tal modo que podemos conocer intelectualmente más y mejor, y siempre podemos amar más y mejor. De todas formas, por mucho que desarrollemos las potencias naturales nunca seremos capaces de realizar operaciones que excedan nuestra naturaleza. La gracia se apoya en la naturaleza, pero la supera: nos hace capaces de realizar operaciones que exceden completamente las fuerzas naturales. La gracia aparece así, desde el punto de vista metafísico, como una ampliación o intensificación del acto de ser que trasciende los límites de la naturaleza permitiendo realizar operaciones "sobrenaturales". Esta intensificación del acto de ser hace romper, por así decir, los límites estrechos de la naturaleza para aspirar alcanzar lo que de algún modo le excede por completo: amar y conocer a Dios, o más precisamente participar de su misma vida divina. En palabras de Gea Escolano a propósito de Ledesma:

El hombre elevado por la gracia tiende a Dios, no como autor del orden natural, sino a Dios sicuti est. Tiende a poseerle tal como es, por conocimiento 
y amor. Por la gracia desaparece la desproporción que había del hombre respecto de Dios. Dios trascendía al hombre. Por la gracia el hombre ha participado de esa trascendencia divina, pues por ella adquiere el hombre la plenitud de su ser. Dios trascendía al hombre porque el ser natural de éste era limitado, determinado por la esencia humana. La gracia transforma esa limitación del ser humano, haciendo que el ser que había en el hombre, adquiriese sus características propias, elevando al hombre al plano divino o sobrenatural (Gea 1960b, 628).

La experiencia de los místicos, como la de san Juan de la Cruz, nos habla de esta liberación de los límites de la naturaleza humana para entrar en la vida divina (Gea 1960b, 602). Se comprende así cómo la doctrina metafísica del acto de ser no es una mera abstracción especulativa, sino que está encaminada a la contemplación y participación de la vida divina, y por tanto a la caridad, en comunión íntima con Dios (Orrego 2004; Verdú 2019).

\section{LA TAREA DEL TEÓLOGO Y EL FIN DE LA TEOLOGÍA}

En la segunda meditación previa a su comentario de la q. 1, al tratar de la estructura de la Summa, Báñez afirma que Tomás de Aquino después de tratar de Dios y la creación, en la segunda parte estudia las acciones que nos dirigen a Dios y a la salvación: "puesto que el fin de nuestra fe y de las sagradas Escrituras es que los miserables consigan la salvación, es necesario que el Doctor teólogo, como celestial médico de las almas, se dedique intensamente a lo que se relaciona con la salvación de las almas" (Báñez 2020, 69). Con estas palabras Báñez toma distancia de una teología abstracta ajena a la suerte de los hombres. El teólogo actúa como un médico, instrumento divino para la salvación:

Considero que el hombre, por el pecado original de nuestro primer padre, ha sido abandonado como el más miserable, herido y medio muerto. Para curarle, además de las disciplinas físicas ${ }^{2}$, es necesario utilizar otra ciencia de salvación. El teólogo, que hace las veces de Dios salvador, se prepara para presentarse como doctor idóneo de esa ciencia que ha sido dada por Dios para la remisión de los pecados; ante todo es necesario, como suelen hacer los

2 Báñez no se refiere únicamente a las "ciencias físicas o cosmológicas" sino a toda ciencia que puede alcanzarse con las fuerzas de la razón natural. 
médicos de los cuerpos, que controle el pulso de la arteria del enfermo [...], y que piense y recete el remedio medicinal en el tiempo oportuno (Ibidem).

Por consiguiente, el teólogo hace las veces de Dios salvador, y todo su saber se debe encaminar a la salvación de las almas, esto es, la vida de la gracia. Así pues, la Teología posee una dimensión práctica que no puede ser relegada; tiene por fin dirigir nuestras acciones al amor de Dios; y desde el punto de vista humano, a la felicidad. "La Teología [...] en buena parte trata sobre los medios por los que la felicidad puede alcanzarse. Aparte de esto, por parte del alumno cualquier ciencia por muy especulativa que sea, puede dirigirse a la alabanza y culto a Dios" (Báñez 2020, a. 4, duda 1ª 148). En este contexto, Báñez cifra el ideal del teólogo en la vida de santidad, como requisito para el óptimo ejercicio de la Teología:

La razón superior, en cuanto trata sobre Dios como objeto sobrenatural, contemple y busque de modo más alto lo divino; pero esto lo hace mediante la fe y los dones sobrenaturales. De aquí se sigue que en igualdad de condiciones será más sabio en Teología quien tenga caridad que el que no la tenga, porque sin caridad no se unen tales dones del Espíritu Santo a la fe, que ilumina la mente y da inteligencia a los niños. Por lo que vemos que los egregios teólogos estaban dotados de una santidad no mediocre (Báñez 2020, a. 4, duda 1a , 148).

En definitiva, la especulación no está desligada de la caridad y debe llevar a la santidad, es decir, a la contemplación del Dios vivo. Como apuntábamos anteriormente, el saber teológico se encamina a la transformación del hombre, a la divinización de la criatura. Por consiguiente, mística y especulación no se contraponen, sino que mutuamente se enriquecen. La connaturalidad con Dios supone un mayor conocimiento de las cosas divinas; y si el teólogo personalmente no ha alcanzado la santidad eximia que sería de desear, al menos el trato con personas santas enriquecerá su conocimiento de Dios. Por eso, según el maestro salmantino, el testimonio de los santos es relevante para el ejercicio de la Teología:

Y así, cuando los santos dilucidan con alguna interpretación, con modestia y paso a paso, un pasaje oscuro, no cierran a los que vengan detrás el camino para interpretar ese mismo pasaje con nueva atención, pero con veneración a los antiguos padres. Pero cuando todos los santos afirman con firmeza que un determinado pasaje se ha de interpretar así o de otra manera, sería más que temerario no concordar con ellos, y mucho más rechazarlo. [...] Por tanto, nos es lícito, siguiendo las huellas de los santos, recoger algunas espigas que escaparon a las manos de los cosecheros [...] Quizás, caminando por esta vía 
con humildad, seamos dignos del tálamo regio de Cristo (Báñez 2020, a. 10, duda $\left.7^{\mathrm{a}}, 275-276\right)$.

Báñez habla de la santidad del teólogo, empleando un lenguaje propio de los místicos (el tálamo nupcial). Al tratar del quehacer teológico, Báñez afirma que la Teología ha de comenzar realizándose en un orden de connaturalidad o cercanía con lo divino, solo posible gracias a la fe y a los dones del Espíritu Santo. De esta manera, la Teología obtendrá luces muy provechosas, antes que la razón halle conclusiones. Citando a Báñez, Garrigou-Lagrange afirma: "los teólogos después de haber pasado los años entregados al estudio de la Teología, sacan gran provecho del trato con personas espirituales [...] no es posible que se den cuenta exacta de las inmensas riquezas espirituales contenidas en los tratados que explican; y hasta corren riesgo, si explican teología positiva, de convertirse, sobre todo, en historiadores; o, si explican la teología especulativa, de no pasar de lógicos o metafísicos" (Garrigou-Lagrange 1998, 1240)-La vida de la santidad y de la humildad es el camino adecuado para progresar en el conocimiento de Dios; pero no un conocimiento meramente intelectual, sino vital, del amor y de los afectos espirituales. Por esta razón creo razonable hablar de una influencia positiva de la mística en los comentarios bañecianos (García Cuadrado 2016a).

\section{SABIDURÍA Y UNIDAD DEL SABER TEOLÓGICO}

Para Báñez, la Sagrada Doctrina se vincula, por tanto, con el acto de fe -acto vital o existencial-, y más concretamente con la vida de fe y con la sabiduría vinculada al conocimiento por la fe. En otras palabras, la experiencia de Dios forma parte de la Sacra Doctrina; es más, viene a ser el fundamento y punto de partida de la reflexión teológica. Para Báñez la revelación consiste principalmente en "la iluminación del sujeto, mucho más que en el descubrimiento del objeto" (Latourelle 1977, 208). La diversidad de los saberes encuentra su unidad en el sujeto que cree y razona. Las distinciones de las diversas disciplinas teológicas (dogmática, exégesis, moral y espiritual, etc.) ha provocado una fragmentación de los saberes teológicos suscitando aparentes yuxtaposiciones (teología especulativa y la mística) hasta el punto de que hoy en día parece imposible volver a obtener una síntesis de los diversos saberes sobre Dios (Torrell 1998, 11). Pero esta fragmentación del saber teológico no se encuentra todavía en los escolásticos salmantinos, ni concretamente en Domingo Báñez. Sus comentarios no sólo manifiestan un riguroso ejercicio especulativo sino también una experiencia de fe vivida. En este sentido "la Sacra Doctrina es para él [Báñez] tanto la fe, como la profecía, como la doctrina fundada en la fe, es 
decir, la Teología, cuyas funciones a su vez abarcarán la interpretación de la Escritura, su inteligencia y su anuncio, la inferencia de conclusiones a partir de la revelación y la labor argumentativa en general" (Martínez 1973, 306). Así pues, la Sagrada Doctrina es en primer lugar, fe; pero una fe que asume el discurso de la razón potenciándola: la teología no consiste en Báñez en una aplicación de la filosofía al contenido revelado, sino que es una potenciación de la fe en el creyente que es al mismo tiempo filósofo (Congar 1981, 179; Javierre 1949).

Siguiendo las enseñanzas bañecianas se podría concluir que la experiencia del creyente es fuente principal de la Teología, superando así la separación indebida entre mística y teología escolástica. En tiempos de Báñez -y santa Teresa- ese antagonismo se vio reflejado en la oposición entre "escolásticos" (especialmente dominicos) y "recogidos". En efecto, había comenzado a extenderse entonces un tipo de religiosidad más intimista -"mística del recogimiento"- cultivada especialmente en el seno de la orden franciscana, unida a la religiosidad de los "alumbrados". Esta nueva espiritualidad no estuvo exenta de desviaciones y excesos que santa Teresa quiso evitar, acudiendo a religiosos doctos que garantizaran la ortodoxia doctrinal. En este sentido es muy significativo que fuera Báñez el censor del libro de la Vida de Teresa de Jesús, publicado en Salamanca en 1588 (Báñez, 1982). En este contexto, la ayuda que Báñez prestó a la reforma carmelitana fue decisiva, no sólo por la solidez de sus principios teológicos, sino también por el prestigio intelectual que gozaba en el seno de la Universidad. Este apoyo a la reforma de la espiritualidad hay que entenderla en un contexto más amplio: revela una convicción profunda de que la teología, en virtud de su carácter sapiencial, no puede prescindir de la dimensión espiritual del creyente.

\section{VALORACIÓN CONCLUSIVA}

En el breve espacio de este artículo no es posible siquiera esbozar el estado de la cuestión de las relaciones entre especulación teológica y experiencia mística o, en versión pascaliana, la yuxtaposición entre el dios de los filósofos y el Dios de la fe. Pero hay un hecho cierto: a lo largo de la segunda mitad del siglo XVI y comienzos del XVII se dio un momento de esplendor especulativo en la teología escolástica, junto a las más altas cimas de la mística castellana. Mi propuesta es que ambos hechos no fueron contrarios, ni siquiera paralelos. En el fondo, bastaría acudir a la experiencia interior: amamos aquello que concebimos como bueno; y cuanto más conocemos la bondad de lo amado, más se despierta el deseo de conocerlo mejor y poseerlo por el amor. Es la persona entera la que 
conoce y ama: el conocimiento de Dios "deifica", dado que se crea una cierta connaturalidad con la realidad divina.

Ahora estamos en condiciones de aquilatar mejor la supuesta separación entre especulación teológica y santidad. En el comentario de Báñez a la II-II, q. 23, cuando el Doctor Angélico se pregunta si es posible la amistad con Dios, el maestro salmantino -siguiendo la doctrina aristotélica-objeta que no es posible dada la desproporción entre la naturaleza divina y la humana.

Si alguien dijera: es suficiente que Dios mediante la creación nos comunicara gratuitamente el mismo ser de la existencia, y que en esta gratuita comunicación puede fundarse la amistad. Se responde, en primer lugar, que Aristóteles no conoció la gratuita creación de las cosas, sino que pensó que el mundo procedió eternamente de Dios de modo natural, $[\ldots]$ y por tanto según la opinión de Aristóteles no puede fundarse la amistad en esta comunicación y operación divina. Se responde que a pesar de que puede conocerse naturalmente a Dios como liberal autor de la naturaleza que produjo el mundo, ya sea desde la eternidad o ya sea en el tiempo; sin embargo, el mismo ser de existencia es común también a las cosas inanimadas; luego no puede fundarse [en él] una especial amistad hacia Dios (Báñez 1584, 818e).

Báñez recurre de nuevo a la metafísica del ser: siguiendo a Aristóteles, no hay don gratuito del ser, pues desconoce la doctrina de la creación. Además, el mero existir es común a todos los seres, incluso los inanimados, el grado ínfimo de existencia: ¿Cómo establecer una comunión amistosa entre naturalezas tan distantes? Es cierto que el hombre puede conocer a Dios y tenerle un cierto amor como sumo bien; pero esto no puede llamarse con propiedad amistad. Además, uno de los requisitos para la amistad es que esta no permanezca desconocida para los amigos (Báñez 1584, 815a-b).

Báñez refuta los diversos argumentos aristotélicos sobre la amistad para afirmar que entre el hombre y Dios pueda darse una verdadera y propia amistad, aunque actualmente esta sea imperfecta.

La caridad en vía es imperfecta con respecto a la caridad en patria; y por eso no hay que admirarse ni hay inconveniente en que en su género carezca de consumación que postula la perfecta razón de amistad. De donde, aunque de algún modo se nos oculta, si somos amigos de Dios, no se destruye la especie de amistad, sino que es signo de su imperfección. Sin embargo, incluso en este estado de algún modo hay ciertos justos por el testimonio de la buena conciencia y de las buenas obras. Y esto también es suficiente para la amistad humana, que por las conjeturas conozcamos que nos agrada el amigo: aunque no vemos las cosas ocultas de su corazón (Báñez 1854, 820b). 
Ciertamente, desde el punto de vista de la mera naturaleza, no sería posible hablar de verdadera amistad entre Dios y la criatura racional. Pero esa distancia no existe cuando se trata de la comunicación de gracia, puesto que "la ausencia no es óbice para que la caridad sea amistad, [...] ya que está presente de modo verdaderamente real por la gracia, la cual actúa en nosotros, y se conserva por los auxilios que presta al amigo" (Báñez 1854, 820c). En definitiva, los textos de las Escrituras nos hablan propiamente de la relación de amistad de Dios con sus criaturas (Báñez 1854, 820 d-821c). Todos estos sentidos se pueden justificar porque hay una comunicación en la gracia, y si la entendemos como una gratuita intensificación del acto de ser que desborda los límites de nuestra naturaleza y nos "deifica" haciéndonos semejantes a él. En definitiva, la aparente distancia insalvable entre Dios y las criaturas puede acortarse gracias a la vida de la gracia, que en Báñez y en sus discípulos puede ser entendida en términos de la metafísica del ser.

\section{REFERENCIAS BIBLIOGRÁFICAS}

Almeida Rolo, Raul. 1976. "Duas linhas de restauração tomista na segunda Escolástica do século XVI". En Atti del Congreso Internazional em ell VII centenário. Napoli, : 230-241. Edizione Domenicane Italiane.

Alvira, María Isabel. 1992. Vision de l'homme selon Thérèse d'Avila. Una philosophie de l'héroïsme. Paris: Fx. de Guibert CEIL.

Andrés, Melquíades de. 1977. La teología española en el siglo XVI. Vol. 2. Madrid: BAC.

Balthasar, Hans Urs Von. 1964. "Teología y santidad”. En Verbum caro. Ensayos teológicos. Vol. I, 235-251. Madrid: Cristiandad.

Báñez, Domingo. 1584. Scholastica Commentaria in Secundam Secundae Angelici Doctores Thomae, quibus, quae ad Fidem, Spem et Charitatem spectant, clarissime explicantur usque ad XLVI quaestiones. Salamanca: S. Stephanum.

Báñez, Domingo. 2020. La Sagrada Doctrina, traducción de A. C. Chacón; introducción y notas J. A. García Cuadrado. Madrid: Sindéresis.

Báñez, Domingo. 1982. Censura al libro de su Vida: Santa Teresa de Jesús, en Obras Completas (Madrid: BAC): 25-28.

Belda, Juan. 2000. La Escuela de Salamanca y la renovación de la Teología en el siglo XVI. Madrid, BAC.

Bonino, Serge-Thomas. 1994. "La historiografía de la Escuela tomista: El caso Gilson”. Scripta Theologica 26: 955-976.

Congar, Yves. 1981. La fe y la teología. Barcelona: Herder.

Forment, Eudaldo. 1985. "El ser en Domingo Báñez". Espíritu 34: 25-48. 
García Cuadrado, José Ángel. 2016a. "Mística y Escolástica: la influencia de santa Teresa de Ávila en Domingo Báñez". Scripta Theologica 48: 41-58.

García Cuadrado, José Ángel. 2016b. "Gilson y Báñez: luces y sombras de un encuentro tardío". Studia gilsoniana 5: 579-618.

García Cuadrado, José Ángel. 2018. "Gilson y el redescubrimiento de la metafísica de Báñez". En Opere et veritate. Homenaje al profesor Ángel Luis González, editado por E. Alarcón, A. Echavarría, M. García-Valdecasas, R. Pereda, 311-323. Pamplona: Eunsa.

García Fernández, Manuel, 1946-1947. "La gracia como participación de la divina naturaleza en Juan de Santo Tomás y lugar que a éste corresponde en la tradición tomista". La Ciencia Tomista 71: 209-250; 73: 5-62.

Gea Escolano, José. 1960a. "El ser divino y su participación en el orden natural en Pedro de Ledesma". Salmanticensis 2/7: 361-417.

Gea Escolano, José.1960b. "La gracia como participación especial de Dios a través del ser, en Pedro de Ledesma". Salmanticensis 3/7: 579-629.

Gutiérrez Vega, Luis. 1954. "Domingo Báñez, filósofo existencial”. Estudios Filosóficos 3: 83-114.

Huerga, Álvaro. 1963. "I domenicani nella vita e nella reforma di santa Teresa". Rivista di vita spirituale 17: 458-474.

Huerga, Álvaro.1966. "Teología espiritual y teología escolástica”. Revista española de teología 26: 3-34.

Javierre, José María. 1949. "La razón en teología según Domingo Báñez”. La Ciencia Tomista76: 258-297.

Klauck, Hans-Josef. 1970. "Der Bruch zwischen Theologie und Mystik". Franziskanische Studien 52: 53-69.

Latourelle, René. 1977. Teología de la revelación. Salamanca: Sígueme.

Ledesma, Pedro de. 2011. Sobre la perfección del acto de ser creado (1596), introducción, traducción y notas por S. Orrego Sánchez. Pamplona: Eunsa.

Lépée, Marcel. 1947. Báñez et Sainte Thérèse. Paris: Desclée de Brouwer.

Maroto, Daniel de Pablo. 2009. Lecturas y maestros de santa Teresa. Madrid: Editorial de Espiritualidad.

Martínez, Luis. 1973. Fuentes para la historia del método teológico en la Escuela de Salamanca. Vol. II. Granada, Facultad de Teología.

Moioli, Giovanni, 1978. "Sapere teologico e sapere proprio del cristiano. Note per un capitolo della letteratura spirituale e della teología". La Scuola cattolica 106: 569-596.

Montero, Aristónico. 2015. "Santa Teresa y el P. Domingo Báñez O.P.”. Studium 55: 355-408.

Orrego, Santiago. 2004. "Pedro de Ledesma (Salamanca, s. XVI): contemplación mística de la realidad creada desde el acto de ser". Mediaevalia. Textos e Estudos 23: 371-383. 
Orrego, Santiago. 2006. "El tratado de Báñez sobre la existencia creada: Génesis y sentido de una cumbre metafísica". En El alma humana: esencia y destino, editado por Cruz González-Ayesta, 193-200. Pamplona: Eunsa.

Osuna Fernández-Largo, Antonio. 1997. "Domingo Bañez". En La filosofía española en Castilla y León: de los orígenes al Siglo de Oro, editado por M. Fartos Martínez, coord., 369-381. Valladolid, Universidad.

Pascal, Blaise. 2018. Pensamientos. Madrid: Tecnos.

Pena González, Miguel Anxo. 2009. La Escuela de Salamanca: de la monarquía hispánica al orbe católico. Madrid: BAC.

Sánchez Sorondo, Marcelo. 1977. "La noción de participación en Juan Vicente y sus problemas". Salmanticensis 24: 335-350.

Urdanoz, Teófilo. 1945. "Juan de Santo Tomás y la transcendencia sobrenatural de la gracia santificante". La Ciencia Tomista 69: 48-90.

Torrell, Jean-Pierre. 1998. Tommaso d'Aquino, maestro spirituale. Roma: Città Nuova.

Vanderbroucke, Frank. 1950. "Le divorce entre Théologie et mystique: ses origines". Nouvelle revue théologique 72: 372-389.

Verdú, Ignacio. 2019. "Amor y metafísica. Una reflexión acerca de la filosofía primera". Cauriensia 14: 117-130.

Vilanova, Evangelista. 1989. Historia de la teología cristiana. Vol. 2. Barcelona: Herder.

José Ángel García Cuadrado Instituto de Estudios Hispánicos en la Modernidad (IEHM) Universitat de les Illes Balears. Cra. de Valldemossa, km. 7,5 07122 Palma de Mallorca (España) https://orcid.org/0000-0002-6881-5981 
